\title{
Dissociation: Normal or Abnormal?
}

\author{
Marlene Spencer, M.Ed. \\ University of Alberta
}

ABSTRACT: Recent articles have addressed the question of whether or not the out-of-body experience reported by many people near death is a form of dissociative behavior. If so, is it related to other mental or emotional pathologies or is it a normal protective response to stress? This paper explores the history of dissociation and related terms, uncovering a multiplicity of uses and connotations. New orientations in physics and the rise of the New Science in the form of Chaos Theory allow a plethora of additional interpretations.

The out-of-body experience (OBE) is one of the most dramatic and memorable features of the near-death experience (NDE). That it has been reported by individuals not near death, during a variety of altered, traumatic, or volitional states, makes it special amongst other NDE phenomena. Glen Gabbard and Stuart Twemlow (1986) discussed the OBE as an altered mind/body state that is spatial rather than temporal, which is characteristic of dissociative states. This implies a qualitative difference between the OBE and dissociation. Yet the Winter 1993 issue of this Journal contained two article that further confused the issue of the appropriate definition and use of the term dissociation.

Authors William Serdahely (1993) and Harvey Irwin (1993) presented different theoretical constructs to explain dissociation. Serdahely wrote:

Marlene Spencer is a Ph.D. candidate in Educational Psychology at the University of Alberta in Edmonton. Her dissertation explores the experiences of people who are near death. The author appreciates the contribution of W.H.O. Schmidt, Professor Emeritus, Department of Educational Psychology, University of Alberta, for bringing historical accuracy to some of the author's interpretations of the development of the discipline. Reprint requests should be addressed to mss@gpu.srv.ualberta.ca or Bruce Bain, Ph.D., at the Department of Educational Psychology, University of Alberta, Edmonton, Alberta, T6G 2G5, Canada. 
I suggest that the OBE is one stage of a continuum of dissociation from the physical body . . . . The antithesis of dissociation then is association, being able to associate with a physical body, the end point of which is being totally centered in the body. (1993, pp. 93-94)

On the botton of the facing page, Irwin offered:

Dissociation may be defined as a stuctured separation of such mental processes ... . . That is, feelings may be separated or "dissociated" from memories of specific incidents, and some memories may be kept separate or "repressed" from the flow of conscious thought. (1993, pp. 95-96)

Serdahely discussed a quantitative separation of the person or personality from the physical body. Irwin saw a separation of "mental processes" one from the other, not from the body. Even more nonspecific, psychologists are often trained to use the term to refer to a lack of common experience between parts of a single individual. This still leaves one unsure of the dynamics, processes, or even the hermeneutics of such a situation.

This article is an attempt to trace the historical origin of the term dissociation and notions asociated with it, to fill a gap in the understanding of the term, and to aid the reader in deciding if dissociation includes or excludes the OBE. Further, if the OBE is a form of dissociation, is it normal or abnormal? Is dissociation itself protective or pathological?

\section{Historical Perspectives on Dissociation}

An individual can control his or her perception of events by creating or escaping to other realities. One means by which one may access other realities is through dissociation. Early in the 19th century, young Mary Reynolds presented with two dissimilar personalities. This condition was epitomized by Robert Louis Stevenson in his Dr. Jekyll and Mr. Hyde (1886). Earlier, demonic possession had been thought to result in similar behavior. In hypnosis it was noted as well that often the personality seemed divided. As the person was in trance, a part of the person appeared to be aside, observing and protecting rather than participating. This was referred to as doubleconsciousness or doubled-ego in the writings of the 1890s (Hilgard, 1987). Bessel van der Kolk and Onnon van der Hart (1989), representative of the several journal contributors celebrating the centen- 
nial of Pierre Janet's dissertation, defined Janet's notion of dissociation as "the crucial psychological process with which the organism reacts to overwhelming trauma and which results in the wide variety of symptoms then classified under the rubric of 'hysteria" (p. 1532). Arnold Ludwig offered another definition:

Dissociation represents a process whereby certain mental functions which are ordinarily integrated with other functions presumably operate in a more compartmentalized or automatic way usually outside the sphere of conscious awareness or memory recall. $(1983$, p. 93)

The current edition of the American Psychiatric Association's Diagnostic and Statistical Manual of Mental Disorders, the DSM-IV (American Psychiatric Association, 1994) began its discussion of dissociative disorders as follows:

The essential feature of the Dissociative Disorders is a disruption in the usually integrated functions of consciousness, memory, identity, or perception of the environment. The disturbance may be sudden or gradual, transient or chronic (p. 477)

Among the five categories of dissociation listed were Depersonalization Disorder and Dissociative Disorder Not Otherwise Specified. The DSM-IV recognized that these categories do not fit recognized syndromes. These are instances where a symptom is given a label because a coherent theoretical or obvious disease process is lacking or where the symptom is found in association with other phenomena. Frank Putnam (1989) included descriptions of dissociative disorders not included in previous editions of the DSM, such as hypnoid states, somnambulism (DSM-IV included this as Sleepwalking Disorder under the general category of Sleep Disorders), possession states, and out-of-body and near-death experiences. "In dissociation an aspect of the experience is kept out of conscious awareness" (Brown and Fromm, 1986, p. 11).

Janet (1859-1947) is credited with the first use of the term dissociation. This phenomenon was in need of a name, as several clinicians were encountering it in their practices. Janet described and named dissociation in his doctoral dissertation, Automatisme Psychologique, published in 1889 at the Salpettrière in Paris. Jean-Marie Charcot, the "Napoleon of Neuroses" (Ellenberger, 1970, p. 95) and leader of the great French school and hospital of the latter 19th century, was mentor to the young Janet, and was his thesis supervisor (Janet, 1889). Charcot died unexpectedly just two weeks after Janet successfully defended his thesis in medicine. 
In 1882, Mesmerism had taken clinical form under the name hypnosis as treatment for hysteria. Charcot, also dubbed "the Prince of Neurophysiologists," presented a paper to the skeptical French Academy of Science, who when approved its use in medicine (Kelly, 1991). It was with this act that the perennial mind/body problem moved from scholars in philosophy and theology and appeared in modern medicine.

During the hundred years between Franz Mesmer and Charcot, animal magnetism was replaced with will, concentration, lucid sleep, somnambulism, psychotherapeutics, and a plethora of other terms (Guillian, 1959). Medicine, despite the fact that its own sons were leaders in the fight to establish hypnotism as a valid medical practice, always refused to adopt medical psychology (Zilboorg, 1967).

The Salpêtrière was an asylum and prison housing 5,000 women that, under Charcot's leadership, became the world's leading medical center for clinical neurologic research (Guillian, 1959). By the 1880s Charcot had become interested in hypnosis as a therapy for hysteria, and published his Lessons on Illnesses of the Nervous System (18801883). He had many disciples and students and thousands of admiring patients. Evidently he had some detractors as well. That Charcot was an effective and influential teacher cannot be questioned. Sigmund Freud won a traveling scholarship to Paris in 1885 to study under Charcot. He was, prior to his Paris trip, ignorant of hypnosis. The impact of his Salpêtrière study evoked the thinking that was to influence the course of psychology's study of the mind for the entire 20th century (Hilgard, 1987).

When Janet formulated his notions of dissociation in 1889 , it was the historical consequence of generations of clinical observation and the development of psychology as a discipline (Haule, 1986). For an idea whose time has come, history must provide an individual in whom the idea can germinate and receive expression. In this case, history provided a veritable beehive of individuals who worked in concert or at odds, stimulating, prodding, and leading one another in an atmosphere of scholarly excellence and professional competition, so that there grew much animosity regarding credit for the first ideas. The animosity created much development of theory, careful clinical observation, and effective documentation.

Hippolyte Bernheim joined the new School of Nancy as its leader in 1872 (Kelly, 1991). He had become interested in hypnotism after referring a patient, whom he had treated unsuccessfully for six years, to a country doctor, Auguste Ambroise Liébeault, who had received 
much success and notoriety using the unorthodox treatment. The patient was immediately cured by Liébeault's method. Bernheim undertook the study of the treatment, publishing his classic De la Suggestion dans l'état de veille in 1884.

There was much competition between Bernheim of the Nancy School and Charcot of the Salpêtrière. Their differences centered on diverse theoretical orientations toward hypnosis (Kelly, 1991). Bernheim saw hypnosis as a psychological phenomenon; Charcot saw it as a physiological one. Bernhein saw hypnosis as a normal state; Charcot saw it as an abnormal state.

Janet, as Charcot's intellectual successor, viewed dissociation as a pathological state. His use of the term dissociation derived from the then popular theory of association. Associationist theory held that learning and memory were based upon an association of ideas. The notion of the association of ideas as representative of the structure of the mind was first articulated by John Locke (Hilgard, 1987). A few hundred years of elaboration made that model of cognitive function predominant. James Mill, John Stuart Mill, Alexander Bain, and William James were exponents of associationism. If the structure of the intellect consisted of associations of ideas, why could one not call the deterioration of the fabric of the mind into component parts dissociation?

It is important today to study Janet's hundred-year-old notion of dissociation and follow its development in order to understand the need to revise our present use of the term to cover new syndromes and treatments of which we are just becoming aware. Three Americans, associated as the Boston School (Hilgard, 1987), continued to observe, elaborate, and use the construct of dissociation.

James, philosopher and psychologist, Harvard University professor under whom the first American psychological laboratory was founded, chronicler of the thinking of his age, brought us up to date with scientific thought in turn-of-the-century Western Europe. His Principles of Psychology (1890) was a most readable treatise on who was thinking, researching, and teaching what. Information of this type was greatly needed in adolescent America. James educated the American intellect. His Principles was the basic text in psychology for generations. James acquainted American scholars and researchers with the techniques of hypnosis and the phenomena of dissociation.

By 1902, a student of James's, Boris Sidis, psychologist, director of the laboratory of the Psychopathic Hospital, Department of the New York Infirmary for Women and Children, had developed a clinical back- 
$\log$ of case histories to support a very coherent theory of pathological dissociation. His model featured a progression of mental disintegration of systems by phases and stages, each represented by an illustrative clinical expression in his book Psychopathological Researches in Mental Dissociation (1902). That Sidis was a student of James was clearly illustrated by his introductory chapter on functionalism and the use of the method of introspection. His was a model of unified mind/body (psychic and neuronal) expressions of dissociation:

The whole pathological process with its stages and concomitant psychomotor manifestations, may thus be conveniently subdivided into three great classes, one passing into the other by imperceptible degrees: functional psychosis, functional neuropathy, and necrotic neuropathy ... neuron degeneration, stages which for lack of a better name may be termed necrotic neuropathies. (1902, p. xii)

Of course, the cure for dissociations and disintegrations would be "reassociation, or synthesis of dissociated systems . . . from a therapeutic standpoint, synthesis is cure" (Sidis, 1902, p. xx). Cure was complicated by the fact that, according to Sidis, neuropathies are purely organic: "Unlike the functional psychoses, the neuropathies have no subconscious 'equivalents' .... No synthesis is possible" (1902, p. xiv).

Sidis has all but been forgotten; he is hardly more than a footnote in the history of psychology. Yet his notion of mental deterioration is unique in that it did not reflect the usual Cartesian polarizations. He viewed psychological and physiological dysfunctions on the same continuum. The main features separating the two were not the behavioral manifestations, but the degree of organicity, and thus the "curability."

Sidis coedited the Journal of Abnormal Psychology, founded in 1906, with Morton Prince (Ross, 1989), who became perhaps the best known authority on multiple personality disorder with his book The Dissociation of a Personality (1905/1978). Prince was a founder of the Psychological Clinic at Harvard and is credited with being an early proponent of psychotherapy and a user of hypnosis (Hilgard, 1987). Prince concluded that dissociation could not be purely physiological. Despite his illustrious career, "Multiple personality disorder, like hysteria, came to be regarded as an artifact of hypnotic suggestion" (Frischholz, 1985, p. 103).

The notion of dissociation as a pathological condition had persisted for almost a century. During that time, Freud eclipsed Janet in popularity. His ideas took firm hold on popular as well as psychological 
thinking. Initially enthusiastic about the use of hypnosis, Freud soon abandoned it for his own method of free association of ideas as a way to access unconscious events (Higard, 1987; Kelly, 1991). He felt that it was advisable for the person to be fully aware of issues as they arose, as "the Ego strives to maintain contact with reality to preserve its organization" (Kelly, 1991, p. 85). Freud's popularity resulted in the virtual abandonment of hypnosis as a credible therapy until mid-century. The return from war of millions of young men suffering from the psychogenic trauma of their experiences, referred to as shell shock during World War I, provided the impetus to reexamine notions of dissociation. In the interim, the definition of dissociation had changed many times.

Well before Janet, the Scottish physician James Braid (1795-1860) defined hypnotism. Characteristic was amnesia, and the double-conscious state. Ernest Rossi and David Cheek (1988) indicated that this was early recognition of "state dependent" learning and memory, wherein materal that is learned does not generalize to other states of consciousness. Implied also was the notion of split personality, or a splitting of conscious and unconscious processes. That splitting of parts of awareness was what Janet had in mind when he coined the term dissociation. Initially, one had difficulty detecting a difference in usage of the terms dissociation and hypnosis.

As schizophrenia became recognized as a clinical entity separate from hysteria, the phenomenon of splitting or dissociation became associated with that label. The term schizophrenia was introduced by Eugen Bleuler (Rosenbaum, 1980). In fact, split personality and schizophrenia are still synonyms in lay vocabularies. We now view dissociation as another dimension of the trance state (Brown and Fromm, 1986). But parodoxically we find a category of pathology listed in the DSM-IV as Dissociative Disorders with no reference to hypnotherapy nor to dissociation in trance. We do, today, have the dual use of the term: one abnormal, one normal.

\section{Contemporary Diagnostic Approaches to Dissociation}

Is dissociation necessarily a pathological state, as Janet is said to have espoused, or could it be a normal, in fact, healthy, phylogenetically developed response to intolerable physical or emotional trauma (Ludwig, 1983)? Dissociation appears to be commonly encountered in 
populations who have undergone the stress of trauma, but otherwise exhibit no abnormal characteristics. Increase in awareness of child abuse and recognition of Multiple Personality Disorder as a clinical entity focus our attention upon a model that could accommodate the thinking of both antecedent French schools. Putnam wrote:

Many authors conceptualize these different forms of dissociation as lying on a continuum from the minor dissociations of everyday life, such as daydreaming, to the major pathological forms, such as multiple personality. $(1989$, p. 6$)$

Since dissociation can be used as a tool in therapy and as an effective defense during trauma, there was a need to acknowledge a nonpathological form. This model of a continuum from spontaneous trance states to gross pathology is useful.

Dissociation becomes dysfunctional when it interferes with normal life, as with those people who experience amnesia or become selfdestructive, suicidal, manipulative, or aggressive. (Anderson, 1988, p. 26).

Does the fact that only 200 cases of Dissociative Disorder were reported in the world's literature prior to 1930 (Greaves, 1980) indicate a healthy population, ignorant mental health providers, or a rerouting of cases under other labels? We have a large semantic tangle.

In 1977, Ernest Hilgard put forward his neodissociation theory of divided consciousness (Ross, Joshi, and Currie, 1990), in which he postulated both horizontal and vertical "splits" of consciousness. The horizontal split dissociated psychic contents from the conscious. The vertical split is not dissociation, but repression. Thus another source of confusion, the distinction between dissociation and repression, was schematized.

The following is a valuable current description of the dissociated state:

Perhaps most personalities segment for purpose of adaptation and defense .... . The healthy "normal" person functions like a confederation of self-parts. Usually these are covert and are observable more as mood changes. We call these "ego states." Hilgard's "hidden observer" phenomena are probably covert ego states that are sufficiently dissociated, so that pain can be repressed into them (see Hilgard, 1977). This leaves the executive state relatively pain free ... - Cathartic release may require many abreactions since the major personality could not handle the feelings in the first place and can now accept, release, and integrate them only piecemeal. Cognitive restructuring (genuine insight) must accompany or follow release of 
affect. When the emotions resubmitted to the primary states are more than it can handle, it may temporarily withdraw or regress . . . . Underlying personalities and ego states, being "partpersons," do not have the ability to generalize and engage in abstract thinking. They frequently think concretely and illogically like a child. It is common for an underlying personality to plot the destruction of death of the person while believing that it, itself, will survive. (Watkins and Johnson, 1982, pp. 138-143).

Hilgard presented a gallant effort to corral diverse theoretical views under one schema. His model utilized Janet's causal explanation of dissociation, and by postulating horizontal and lateral spits to accommodate both repression and amnesia, he included Freud. More importantly, he left the gate open for more recent interests in dissociative states characteristic of "normal" populations. These include nonpathological, that is, "healthy" and "protective" dissociations.

Currently an important area of public interest is the increasing incidence of "adjustment" disturbances listed in DSM-IV under the heading of Anxiety Disorders as Posttraumatic Stress Disorder (American Psychiatric Associaton, 1994, pp. 424-429). Posttraumatic Stress Disorder has received attention as it appears to be a "presplit" condition. As described earlier by Janet, it is a reaction to overwhelming trauma. Contrary to Janet's thinking, many now believe that the dissociation produced by trauma is not only not pathological, but natural (Ludwig, 1983), common (Ross, Joshi, and Currie, 1990), healthy (Watkins and Watkins, 1990), and protective (Spiegel and Cardena, 1990).

For years it has been proposed that a dissociative response to trauma is not limited to our species (Jaynes, 1976). If true, that would indicate a mechanism that would have begun to develop before differentiation of our phylogenetic order. To illustrate this point, Ludwig (1983) discussed the dissociations that other mammals evidence when faced with mortal danger, such as "playing dead." When killed by predators, most prey do not release "fright" hormones that would render the flesh inedible. The implication that other species may also have out-of-body near-death experiences challenges our ideas regarding the "humanness" of consciousness.

Irwin, citing Putnam, pointed out that the capacity for dissociation develops "in childhood as a normal process intrinsically associated with fantasy and imaginative ability" $(1993$, p. 96). It is the child's developmental nature to construct reality from environmental clues, 
and out of necessity, bridge gaps in logic with creative imagination. For the young, as for the critically ill, the line between common and idiosyncratic realities is not clearly drawn. There seems to be a place neither here nor there, where boundaries ebb and flow in time and space. Inhabiting that space is creative imagination, that same quality so vital to successful relaxation and imagery. In the adult, it is the basis of hypnotizability (Hilgard and Hilgard, 1955) and the ability to dissociate in theory. Perhaps the near-death out-of-body experience is an adaptive utilization of a neotenous behavior.

Although dissociation had been called a "state" of consciousness for a hundred years, it had never really been afforded that label in our thinking. It has been thought of as a characteristic-if given too much, it is unhealthy: something one can do too readily; a trait or correlate of a trait. The existential facts are that we each can and do view our body as the subject of attention or as the object of it (Bain, 1973). In the out-of-body experience, the body is the object of regard. We are looking at ourselves objectively! And never have we thought of the pathological consequences of too little dissociation, or of none at all.

\section{Implications of Contemporary Physics}

Under the heading of "normal dissociations" is a growing interest in what I call recreational or volitional dissociation. Most of the literature generated in the 1960 s by interest in hallucinogenic and other psychotropic chemicals, with altered state research (Tart, 1969) generated by psychotherapeutic techniques, religous cults, brainwashing, psychogenic healing, etc., is currently being resurrected and reexamined under the light of the new thinking generated by the rise of holistic ideology and Chaos Theory (Bohm, 1980; Gleick, 1987; Ruelle, 1991).

Chaos Theory, if it is the mark of a new great paradigm shift, requires a reformulation of all of the models of dissociation referred to in this paper. If chaos is anything it is not linear (Combs and Holland, 1990).

We have been stubbing our noses on the window of the mind since Newtonian mechanics and Cartesian dichotomies molded the Scientific Age. Isaac Newton and René Descartes were the fathers of the linear model from which our thinking springs. Almost all models are linear, as our visual images of explanation are largely limited to the 
two-dimensional page or paper. We have been, for hundreds of years, prisoners of two-dimensional thought. Linear models by nature go from one quality or quantity to another. Hilgard's neodissociation theory is linear, going from the healthy "normal" everyday dissociations to the pathology of the fully split multiple personality. Serdahely's OBE as a "stage of a continuum of dissociation from a physical body" (1993, p. 93) and, as reported by Irwin (1993), his proposal that the NDE and Multiple Personality Disorder are similar phenomena are also linear.

We were aware of the third dimension, as our tactile, everyday existence demonstrated that two dimensions failed to explain the evidence of our other senses, or the experiences of the world. Now we are at the point of realizing that the notion of a three-dimensional universe fails to give us insight into the realm of phenomena such as thinking itself, the world of the mind, and the world of particles of matter too small to observe directly. In other words, we finally understand that the cosmos is composed of that which is beyond our abilities to observe physically and directly. Truth can no longer be determined by our sensory perception of the world alone. In short, there may be a reality we can never know.

Chaos Theory would dictate we accept the notion that all states of consciousness, all alternates, part-persons, and ego states, could exist simultaneously as well as sequentially. In a lively and engaging fashion, Allan Combs and Mark Holland (1990) reviewed the shift brought about in the early 20th century in physics by the mounting number of questions the old mechanistic world of Newton failed to explain. Albert Einstein's general theory of relativity liberated thinking and Werner Heisenberg's quantum theory began to restructure it. The "new physics" leans strongly on the notion of wholeness:

The cosmos is of-a-piece, not empty, but filled with itself, much as a painting is filled with itself. There are foreground and background regions, but the canvas is continuous ... the universe as a continuous, unbroken fabric. (Combs and Holland, 1990, p. xxiii)

Motion and action are also, as is everything, dynamic, continuous, and unbroken; it is the holomovement. We begin to understand what physicists were talking about with the advent of the hologram-but just. We are now familiar with the notion that every part contains the whole; that is, each contains all the information of the whole. David Bohm, the physicist who has done the most retrofitting of his theories of chaos and the "new physics" to psychology to produce a 
unified theory of mind and matter, used the term active information in its literal sense, "to put in form," to describe the manner in which form and shape are given to movement (Bohm, 1990).

We are unaware of the vast spectrum of possible realities by, as Bruce Greyson (1985) pointed out, the nature of our corporeal limitation and our science. There may be parallel realities in cosmic chaos, but we cannot, while alive, range the universe. Perhaps those who are dying, that is, between the states of living and not living, catch a glimpse of chaos, of parallel realities that might abound in the vicinity of life. We cannot know if life continues after death until we make the direct observation. The sweet attraction of death caused by an NDE does change one's attitude toward it. Greyson (1989) remarked that the aftereffects, the altered attitudes, traits, and lifestyles caused by the NDE show it as a phenomenon distinct from other altered states and from other forms of dissociation. Finally, the legacy of such an experience is the insatiable need to know-everything!

\section{References}

American Psychiatric Association. (1994). Diagnostic and statistical manual of mental disorders (4th edition). Washington, DC: American Psychiatric Press.

Anderson, G. (1988). Understanding multiple personality. Journal of Psychosocial Nursing and Mental Health Services, 26(7), 26-30.

Bain, B. (1973). Toward a theory of perception: Participation as a function of body flexibility. Journal of General Psychology, 89, 157-206.

Bohm, D. (1980). Wholeness and the implicate order. Reading, England: Cox and Wyman.

Brown, P., and Fromm, E. (1986). Hypnotherapy and hypnoanalysis. Englewood Cliffs, NJ: Lawrence Erlbaum.

Combs, A., and Holland, M. (1990). Synchronicity: Science, myth, and the trickster. New York, NY: Paragon House.

Ellenberger, H. (1970). The discovery of the unconscious: The history and evolution of dynamic psychiatry. New York, NY: Basic Books.

Frischholz, E. (1985). The relationship among dissociation, hypnosis, and child abuse in the development of multiple personality disorder. In R. Kluft (Ed.), Childhood antecedents of multiple personality (pp. 100-126). Washington, DC: American Psychiatric Press.

Gabbard, G. O., and Twemlow, S. W. (1986). An overview of altered mind/body perception. Bulletin of the Menninger Clinic, 50, 351-366.

Gleick, J. (1987). Chaos: Making a new science. New York, NY: Penguin Books.

Greaves, G. (1980). Multiple personality disorder: 165 years after Mary Reynolds. Journal of Nervous and Mental Disease, 168, 577-596.

Greyson, B. (1985). A typology of near-death experiences. American Journal of Psychiatry, 142, 967-969.

Greyson, B. (1989). Can science explain the near-death experience? Journal of NearDeath Studies, 8, 77-92. 
Guillian, G. (1959). J. M. Charcot: His life-his work (P. Bailey, Trans). New York, NY: Hoeber.

Haule, J. (1986). Piere Janet and dissociation: The first transference theory and its origins in hypnosis. American Journal of Clinical Hypnosis, 29, 86-94.

Hilgard, E. (1987). Psychology in America: A historical survey. New York, NY: Harcourt Brace Jovanovich.

Irwin, H. J. (1993). The near-death experience as a dissociative phenomenon: An empirical assessment. Journal of Near-Death Studies, 12, 95-103.

James, W. (1890). The principles of psychology. New York, NY: Henry Holt.

Janet, P. (1889). L'automatisme psychologique. Paris, France: Alcan.

Jaynes, J. (1976). The origins of consciousness in the breakdown of the bicameral mind. Boston, MA: Houghton Mifflin.

Kelly, W. (1991). Psychology of the unconscious. Buffalo, NY: Prometheus.

Ludwig, A. (1983). The psychobiological functions of dissociation. American Journal of Clinical Hypnosis, 26, 93-99.

Prince, M. (1978). The dissociation of a personality. New York, NY: Oxford University Press. (Original work published 1905).

Putnam, F. (1989). Diagnosis and treatment of multiple personality disorder. New York, NY: Stechert.

Rosenbaum, M. (1980). The role of the term schizophrenia in the decline of diagnosis of multiple personality. Archives of General Psychiatry, 37, 1383-1385.

Ross, C. (1989). Multiple personality disorder: Diagnosis, clinical features, and treatment. New York, NY: Wiley.

Ross, C., Joshi, S., and Currie, R. (1990). Dissociative experiences in the general population. American Journal of Psychiatry, 147, 1547-1552.

Rossi, E., and Cheek, D. B. (1988). Mind-body therapy: Methods of ideodynamic healing in hypnosis. New York, NY: Norton.

Ruelle, D. (1991). Chance and chaos. Princeton, NJ: Princeton University Press.

Sidis, B. (1902). Psychopathological researches in mental dissociation. New York, NY: Stechert.

Spiegel, D., and Cardena, E. (1990). New uses of hypnosis in the treatment of posttraumatic stress disorder. Journal of Clinical Psychiatry, 51 (Suppl. 10), 39-43.

Serdahely, W. (1993). Near-death experiences and dissociation: Two cases. Journal of Near-Death Studies, 12, 85-94.

Tart, C. (Ed.). (1969). Altered states of consciousness: A book of readings. New York, NY: Wiley.

van der Hart, O., and Horst, R. (1989). The dissociation theory of Pierre Janet. Journal of Traumatic Stress, 2, 397-412.

van der Kolk, B., and van der Hart, O. (1989). Pierre Janet and the breakdown of adaptation in psychological trauma. American Journal of Psychiatry, 146, 1530-1540.

Watkins, J., and Watkins, H. (1990). Dissociation and displacement: Where goes the "ouch"? American Journal of Clinical Hypnosis, 33, 1-10.

Watkins, J., and Johnson, R. (1982). We, the divided self, New York, NY: Irvington.

Zilboorg, G. (1967). A history of medical psychology. New York, NY: Norton. 